\title{
Multidimensional forecasting of electricity sales in Hunan Province based on decomposition-integration ideas
}

\author{
Ming Wen ${ }^{1,2}$, Yuan Zhong ${ }^{1,2, *}$, Jing Liao ${ }^{1,2}$, Wenying $\mathrm{Li}^{1,2}$, Hong Zhou ${ }^{1,2}$, and Chufan $\mathrm{Xu}^{1,2}$ \\ ${ }^{1}$ State Grid Hunan Electric Power Company Limited Economic \& Technical Research Institute, \\ Changsha 410004, China \\ ${ }^{2}$ Hunan Key Laboratory of Energy Internet Supply-demand and Operation, Changsha 410004, China
}

\begin{abstract}
As the focus of power companies such as State Grid Corporation of China, electricity sales forecasting is closely related to the development of enterprises and the country. The importance of accurate electricity sales forecasting in the context of electricity reform has become more and more prominent. The article takes electricity sales in Hunan Province as the research object, and constructs a more complete monthly electricity sales forecasting system based on the decomposition-integration idea, correlating electricity sales impact factors, and combining quantitative and qualitative analyses by categories. The prediction results show that the electricity sales forecasting model proposed in this paper has a high prediction accuracy under the existing data capacity level.
\end{abstract}

\section{Introduction}

Since March 15, 2015, my country's power system reform has been steadily advanced. The goal of promoting power system reform is to straighten out the relationship between the state-owned economy, industry interests and economic development. As a key link in the operation of State Grid Corporation of China, electricity sales forecasting is closely related to corporate operating profits. In the context of China's normalization of the economy, economic growth has slowed down, and electricity demand has stabilized. It has become one of the important adjustment tools to intensify the reform of the electricity market, gradually reduce the price of industrial and commercial electricity, bring new investment opportunities to society and enterprises and introduce mixed-ownership reforms in the electricity market to gradually for steadily releasing vitality of the electricity market.

Electricity sales forecast has received much attention from scholars as the basis for decision making and the key to profitability for power companies. There are two types of Benchmark models for electricity sales forecasting. They are mainly traditional econometric models and machine learning models. Traditional econometric models were first applied in electricity sales forecasting, such as Engle et al. (1988).

Therefore, on the basis of previous research, this article takes the monthly electricity sales data of Hunan Province as the research object, based on the decomposition-integration

\footnotetext{
* Corresponding author: zhongy25@hn.sgcc.com.cn
} 
idea, comprehensively uses the empirical mode decomposition (EMD) technology, adopts the ARIMA model in the single sequence forecasting method, and exponential smoothing Model, partial least squares model and support vector machine in the regression prediction method are used as four benchmark forecasting models, considering the nonlinearity and complexity of electricity sales data, identifying different types of electricity sales influencing factor groups. The data sources in this article are State Grid Hunan Electric Power Company and wind database.

\section{Analysis of electricity sales impact factors}

The key to accurate forecasting of electricity sales is to grasp and identify key factors affecting electricity sales. This part first identifies the intensities of different types of impact factors. Secondly, on the basis of intensity analysis, analyze the correlation between impact factors and electricity sales, and identify significant impact factors.

\subsection{Analysis of the intensity of electricity sales impact factors}

The influencing factors of electricity sales are complicated, which can be divided into three categories: high-frequency influencing factors, low-frequency influencing factors, and trend influencing factors. High-frequency influencing factors include weather, temperature and humidity, holidays, etc., which are related to short-term irregular changes in electricity sales.

The EMD decomposition method is used to decompose the monthly electricity sales and various types of electricity sales in Hunan Province from 2014/01 to 2018/12 and integrate them into three categories: high frequency, low frequency, and trend items according to the frequency of the sub-sequence.

Table 1. Analysis of Variance Proportion of Electricity Sales.

\begin{tabular}{|c|c|c|c|c|c|c|}
\hline \multirow[b]{2}{*}{ Sequence } & \multicolumn{2}{|c|}{$\begin{array}{l}\text { High-frequency item } \\
\text { electricity sales }\end{array}$} & \multicolumn{2}{|c|}{$\begin{array}{l}\text { Low-frequency item } \\
\text { electricity sales }\end{array}$} & \multicolumn{2}{|c|}{$\begin{array}{c}\text { Trend item electricity } \\
\text { sales }\end{array}$} \\
\hline & $\begin{array}{c}\text { Correlati } \\
\text { on } \\
\text { coefficie } \\
\text { nt }\end{array}$ & $\begin{array}{c}\text { Variance } \\
\text { as a } \\
\text { percenta } \\
\text { ge of }\end{array}$ & $\begin{array}{l}\text { Correlatio } \\
\mathrm{n} \\
\text { coefficient }\end{array}$ & $\begin{array}{c}\text { Variance } \\
\text { as a } \\
\text { percentage } \\
\text { of }\end{array}$ & $\begin{array}{c}\text { Correlatio } \\
\mathrm{n} \\
\text { coefficient }\end{array}$ & $\begin{array}{c}\text { Variance } \\
\text { as a } \\
\text { percentage } \\
\text { of }\end{array}$ \\
\hline $\begin{array}{c}\text { Total } \\
\text { electricity sold }\end{array}$ & 0.631 & $46.3 \%$ & 0.314 & $11.2 \%$ & 0.677 & $42.5 \%$ \\
\hline $\begin{array}{l}\text { Major in } \\
\text { industry }\end{array}$ & 0.445 & $29.1 \%$ & 0.645 & $34.0 \%$ & 0.612 & $36.9 \%$ \\
\hline Major users & 0.606 & $53.9 \%$ & 0.525 & $15.9 \%$ & 0.659 & $30.2 \%$ \\
\hline Other users & 0.329 & $21.7 \%$ & 0.227 & $10.7 \%$ & 0.841 & $67.6 \%$ \\
\hline business & 0.645 & $33.0 \%$ & 0.191 & $33.4 \%$ & 0.693 & $33.6 \%$ \\
\hline Residents & 0.675 & $50.5 \%$ & -0.098 & $2.3 \%$ & 0.624 & $47.2 \%$ \\
\hline Non-residents & 0.625 & $45.2 \%$ & 0.3 & $2.5 \%$ & 0.739 & $52.3 \%$ \\
\hline Non-ordinary & 0.078 & $48.3 \%$ & 0.729 & $7.4 \%$ & 0.667 & $44.3 \%$ \\
\hline agriculture & 0.637 & $48.6 \%$ & 0.173 & $6.0 \%$ & 0.61 & $45.4 \%$ \\
\hline Bulk sale & 0.491 & $20.6 \%$ & 0.572 & $33.0 \%$ & 0.587 & $46.4 \%$ \\
\hline
\end{tabular}

Table 1 shows the proportion of variance of high-frequency, low-frequency, and trend items in the variation of electricity sales and its correlation with the original electricity sales sequence. It can be seen from the table in the table that the impact factor structure of different types of electricity sales is different, but economic fundamentals all have a strong 
impact on electricity sales, that is, economic fundamentals determine the general direction. The specific conclusions are as follows:

(1) Monthly electricity sales are generally determined by high-frequency impact factors and changes in economic fundamentals. The high-frequency term explanatory factor affects $46.3 \%$ of the electricity sales, and the correlation with the original electricity sales is 0.631 , and the trend item influence factor affects $42.5 \%$ of the electricity sales. The correlation with the original electricity sales At 0.776 , the explanation level of the low frequency term is only $11.2 \%$.

(2) Large users and other users have different proportions of influence factors on electricity sales. The changes in electricity sales by large users are mainly affected by high-frequency influencing factors, with variance accounting for $53.9 \%$, while $67.6 \%$ of changes in electricity sales by other users are determined by economic fundamentals, and the impact of high-frequency influencing factors is significantly lower than Large users sell electricity.

(3) Bulk electricity sales are mainly affected by trend items and low-frequency shadow factors, which account for $79.4 \%$ of the impact.

\subsection{Correlation analysis of influencing factors of electricity sales}

Due to power market-related reforms, social events and other low-frequency impact factors cannot be quantified. The following six major impact factors that can be quantified are mainly considered: temperature, precipitation, industry expansion, income, and manufacturing PMI and non-manufacturing PMI that measure changes in economic fundamentals The correlation between the index and the amount of electricity sold.

The correlation coefficients between electricity sales and the six influencing factors are shown in Table 2.

Table 2. Correlation coefficients of influencing factors of electricity sales.

\begin{tabular}{ccccccc}
\hline & \multicolumn{3}{c}{ High frequency impact factor } & \multicolumn{2}{c}{ Trend influence factor } \\
\hline \multirow{2}{*}{$\begin{array}{c}\text { Electricity } \\
\text { Sales }\end{array}$} & Business & income & precipitat & temperat & Manufacturing & Non-manufacturin \\
& 0.65093 & 0.3679 & ion & ure & PMI & g PMI \\
& 15 & -0.22899 & 0.076973 & 0.200293 & 0.200293 \\
\hline
\end{tabular}

The correlation between business expansion and electricity sales is the strongest, and changes are in the same direction. The manufacturing/non-manufacturing PMI measures the basic trend of the economy. The changes in income, manufacturing/non-manufacturing PMI, and electricity sales are also in the same direction, and the variables are also closely related. The rise of PMI in manufacturing / non manufacturing industry indicates that the economy is running upward and the overall development is showing a good trend. In this context, the overall trend of power sales is also rising. Although the temperature is in the same direction as the change in electricity sales, the increase in temperature will increase the demand for electricity consumption and the electricity sales will increase accordingly.

In summary, there is a close relationship between per capita disposable income, industry expansion, temperature, precipitation, manufacturing PMI, and electricity sales, which have a significant impact on electricity sales.

\section{Monthly electricity sales forecast}

In this study, there are two ideas for forecasting monthly electricity sales: one is to directly predict the monthly electricity sales data; the second is to subdivide the monthly electricity sales into seven categories of electricity sales separately to predict, and to add up the 
forecast results. The input variables used in this study are the six major influencing factors that have a significant impact on electricity sales in the aforementioned empirical analysis. The used forecasting models are shown in Table 3. Comprehensive empirical comparison found that the prediction results based on the decomposition-integration idea after the classification of the monthly electricity sales have higher prediction accuracy than the direct forecast of the monthly electricity sales. Among them, the decomposition prediction method has higher fitting accuracy than the non-decomposition prediction method, and the ARIMA model, exponential smoothing model, and support vector machine regression model have higher prediction accuracy than other prediction models.

Table 3. Summary Table of Electricity Sales Forecast Model.

\begin{tabular}{cccc}
\hline $\begin{array}{c}\text { Forecasting } \\
\text { method }\end{array}$ & $\begin{array}{c}\text { Forecasts without } \\
\text { decomposition }\end{array}$ & Forecasts with decomposition & Best or not \\
\hline \multirow{2}{*}{$\begin{array}{c}\text { Single } \\
\text { sequence }\end{array}$} & ARIMA & STL-ARIMA-ES & $\mathrm{N}$ \\
Forecast & ANN & STL-ANN-ES & $\mathrm{N}$ \\
& & EMD-ARIMA-ES & $\mathrm{N}$ \\
& ES & EMD-ARIMA-ANN-ES & $\mathrm{N}$ \\
Regression & STS & STL-EMD-ARIMA-ANN-ES & $\mathrm{N}$ \\
Forecast & PLS & EMD-SVM -ES & $\mathrm{N}$ \\
& SVM & EMD-SVM-sin-ES & $\mathrm{Y}$ \\
\hline
\end{tabular}

Note: "Y" in the table represents the best prediction model for electricity sales in this study.

Among them, the explanation points are as follows:

(1) The electricity sales of large industries account for more than $50 \%$ of the electricity sales of large users. The electricity sales forecasts of large industries are divided into two modules.

(2) Residents' electricity sales are significantly affected by temperature, especially high and low temperature extreme weather. The prediction accuracy of the model is limited, so the model prediction and the temperature proportional adjustment method are used for prediction. The regression results of residents' electricity sales and temperature show that when the temperature drops by one degree, the residents' electricity consumption drops by $14.6 \%$, and when the temperature rises by one degree, the residents' electricity consumption increases by $14.6 \%$. Therefore, it is necessary to combine the forecasting model of electricity sales and year-on-year adjustment to obtain the best forecasting method for residents' electricity sales.

After modeling the electricity sales of different categories, summing up the forecast results of the electricity sales of each category to obtain the monthly electricity sales forecast values for 2015-2018 and 2019. The forecast accuracy for 2015-2018 before correction is 0.853 . According to the above-mentioned forecasting method, the electricity sales of Hunan province in 2019 are 146.426 billion $\mathrm{kWh}$.

\section{Conclusion}

Electricity forecasting is an important basis for power grid construction planning. In this study, a classification-based decomposition-integration forecasting method is proposed, which organically combines single-sequence forecasting ARIMA, exponential smoothing model, and support vector machine forecasting method, and comprehensively considers the characteristics of influencing factors of different types of electricity sales to construct a electricity sales forecasting model. At the same time, for residents' electricity sales, which 
fluctuate more frequently, the data for certain months were adjusted based on the characteristics of the data while observing the changes in the data.

Based on the results of this study, the EMD-SVM-ES model is suitable for more categories of electricity sales forecasts at the level of data capacity studied in this paper. It is more reasonable to use sub-category research for electricity sales, and sub-category decomposition forecasts are more suitable. Monthly electricity sales forecast in Hunan Province. This study should be reviewed at the end of the month.

\section{Acknowledgment}

This work was supported by Science-Technology Innovation Platform and Talents Program of Hunan Province, China (2019TP1053).

Item Number: B716A220001N

\section{References}

1. Engle R F, Brown S J, Stern G, A comparison of adaptive structural forecasting models for electricity sales[J]. Journal of Forecasting, (7)1988.

2. Smith, Michael, Modeling and Short-Term Forecasting of New South Wales Electricity System Load[J]. Journal of Business \& Economic Statistics, (18)2000.

3. Berry D, The impact of energy efficiency programs on the growth of electricity sales[J]. Energy Policy, (36)2008. 